\title{
Sistema S: LEI, PESSOA JURÍDICA DE DIREITO PRIVAdO E SERVIÇOS CONSTITUCIONAIS NÃO EXCLUSIVOS DE ESTADO
}

\author{
SYSTEM S: LAW, LEGAL ENTITY UNDER PRIVATE LAW AND \\ CONSTITUTIONAL SERVICES NOT EXCLUSIVE TO THE STATE
}

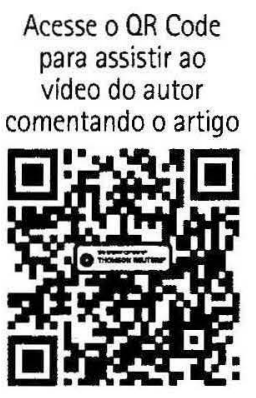

Acesse $O$ QR Code para assistir ao video do autor comentando o artigo

Pós-Doutorado em Direito Tributário pela UERJ e pelo Programa em Democracia e Direitos Humanos do lus Gentium Conimbrigae/Centro de Direitos Humanos associado à Universidade de Coimbra. Doutor em Direito Público pela PUC-SP. Mestre em Direito Constitucional pelo Instituto Brasiliense de Direito Público

(IDP). Especialista em Direito Tributário pela Fundação Faculdade de Direito da UFBA. Especialista em Direito Tributário pelo IBET. Procurador do Distrito Federal e advogado. ORCID: [https://orcid.org/0000-0001-8438-0482]. edvaldonalmeida@yahoo.com.br

Recebido em: 25.10 .2020

Aprovado em: $10.02,2020$ DOI: [https://doi.org/10.48143/rdai.18.ena].

ÁreAs do Diretro: Administrativo; Constitucional

ReSUMO: Este artigo tem por objetivo discriminar os elementos do Sistema $S$, desde sua forma de criação, mediante a edição de lei ou ato normativo equivalente, passando pelo seu objeto, pelo seu regime juridico hibrido e pela discriminação dos serviços constitucionais não exclusivos de Estado. Decerto, fez-se um esboço sobre os elementos constitutivos dos serviços sociais autônomos, iniciando-se por sua gênese juridica, forma de criação das entidades analisadas, bem como os instrumentos legais que podem ser utilizados para tal finalidade e sua organização jurídica. A metodologia consistiu na análise da doutrina e jurisprudência, utilizando-se os métodos bibliográfico e documental, com ênfase nas fontes da Teoria Geral do Direito. Concluiu-se que a conformação jurídica dos serviços sociais autônomos é conferida pelo Estado a partir da lei

\begin{abstract}
This paper aims to discriminate the elements of the S System, from its form of creation, through the publication of a law or equivalent normative act, through its object, its hybrid legal regime and the discrimination of non-exclusive constitutional services of the state. Certainly, an outline was made about the constituent elements of autonomous social services, starting with their legal genesis, the way in which the entities analyzed were created, as well as the legal instruments that can be used for this purpose and their legal organization. The methodology consisted of the analysis of doctrine and jurisprudence, using bibliographic and documentary methods, with emphasis on the sources of the General Theory of Law. It was concluded that the legal conformation of autonomous social services is conferred by the State based on the
\end{abstract}


que cria a entidade. Com relação ao regime jurídico, demonstrou-se que, na relação entre elas e particulares, a regra é a aplicação do regime juridico de direito privado e das normas internas da própria entidade. Noutro giro, como essas entidades prestam serviços de relevante interesse social a partir de repasse de tributos ou de verba pública por meio de contrato de gestão, elas submetem-se ao rigoroso regime de direito público na relação de controle finalístico que o Estado exerce e nas regras de orçamento. Também evidenciou-se que desempenham serviços sociais, elencados no art. $6^{\circ}$ da Constituição Federal, que não são exclusivos do Estado.

Palavras-chave: Serviços Sociais Autônomos Estado - Administração Pública - Reforma administrativa - Lei. law that creates the entity. With regard to the legal regime, it was demonstrated that, in the relationship between them and private individuals, the rule is the application of the legal regime of private law and the internal rules of the entity itself. In another round, as these entities provide services of relevant social interest through the transfer of taxes or public funds through a management contract, they are subject to the strict regime of public law in the final control relationship that the State exercises and in budget rules. It was also shown that they perform social services, listed in art. 6 of the Federal Constitution, which are not exclusive to the State.

Kerwords: Autonomous Social Services - State Public administration - Administrative reform Law.

SumáRio: 1. Introdução. 2. Criação por lei. 3. Pessoas juridicas de direito privado regidas por normas de direito privado e de direito público. 4. Serviços constitucionais não exclusivos de Estado. 5. Conclusão. 6. Referências.

\section{INTRODUÇÃO}

O presente estudo pretende fazer um esboço sobre os elementos constitutivos dos serviços sociais autônomos, iniciando-se por sua gênese jurídica, forma de criação das entidades analisadas, bem como os instrumentos legais que podem ser utilizados para tal finalidade e sua organização jurídica. No âmago da análise sobre os elementos que caracterizam as entidades do serviço social autônomo, inclui-se o seu fim social, no qual se examina quais são os direitos sociais passíveis de prestação por essas entidades e, concomitantemente, a sua ponte com o princípio da subsidiariedade no campo das novas alterações legislativas por parte da União, dos Estados, do Distrito Federal e dos Municípios, que trazem a criação e atuação cada vez mais forte de entidades autônomas com finalidades sociais específicas e com subordinação às exigências do bem comum ou social.

Por sua vez, a demonstração da forma de organização jurídica, finalidades e formas de participação da sociedade na busca dos objetivos sociais dos serviços sociais autônomos serve para demonstrar as balizas constitucionais dentro das quais essas entidades devem funcionar e já corroboram os ares de singularidade máxima e de necessidade de classificação autônoma dos serviços sociais 
Civil, uma vez que não são associações, fundações, partidos políticos, sociedades simples ou empresárias e não possuem sócios ou associados.

Verificou-se que a conformação jurídica dos serviços sociais autônomos é conferida pelo Estado a partir da lei que cria a entidade. Ressaltou-se, nesse contexto, que a própria lei, ou ato normativo equivalente à lei ordinária, efetivamente, faz nascer o serviço social autônomo. Com relação ao regime jurídico a que se submetem as entidades do sistema " $S$ ", demonstrou-se que, na relação entre elas e particulares, a regra é a aplicação do regime jurídico de direito privado e das normas internas da própria entidade. Noutro giro, como essas entidades prestam serviços de relevante interesse social a partir de repasse de tributos ou de verba pública por meio de contrato de gestão, elas submetem-se ao rigoroso regime de direito público na relação de controle finalístico que o Estado exerce e nas regras de orçamento. Ademais, devem atuar na gestão de seus recursos e de seu patrimônio, especialmente no dispêndio de recursos e na contratação de pessoal, a partir dos princípios constitucionais da Administração Pública.

Também foi demonstrado que um dos elementos constitutivos fundamentais das entidades que compõem o sistema " $S$ " é que elas desempenham serviços sociais, elencados no art. $6^{\circ}$ da Constituição Federal, que não são exclusivos do Estado. Esse objeto comum dos serviços sociais autônomos evidencia o propósito de sua criação, desde sua origem, na década de 1940, que é a ampliação da oferta de serviços sociais à população, seja na área da educação, seja na concretização do direito social ao trabalho, seja na atenção à saúde, na assistência social ou em diversos outros aspectos relacionados à cidadania, à dignidade da pessoa humana, aos valores sociais do trabalho e ao pluralismo político (art. $1^{\circ}$, II, III, IV e V, da Constituição).

Do mesmo modo, a definição dos serviços sociais autônomos são entidades que prestam serviços sociais não exclusivos do Estado e não podem exercer atividades para o desenvolvimento de atividade puramente administrativa, típica do Estado. Nesse contexto, demonstrou-se que os serviços sociais autônomos não podem assumir serviços exclusivos do Estado (ADI 1.864-9/PR), em especial, aqueles relacionados às atividades estatais da justiça, segurança pública, fiscalização de tributos e diplomacia. De outro lado, tem-se que os serviços de educação, saúde, alimentação, trabalho, moradia, transporte, lazer, segurança, previdência social, proteção à maternidade e à infância, assistência aos desamparados, todos insertos no caput do art. $6^{\circ}$ da Constituição Federal, são passíveis de execução pela iniciativa privada, com base no próprio texto constitucional.

Evidenciou-se, ainda, que, em se tratando de limitação estatal a atividades econômicas exercidas pelo setor privado, tem-se que a inexistência de limitação constitucional ao seu exercício pelo setor privado implica em autorização tácita 
para a exploração da atividade em razão da aplicação do postulado de direito segundo o qual aos particulares é permitido praticar todos os atos que não lhes sejam vedados. Tem-se, portanto, que o repasse da tarefa de concretização dos direitos sociais por entidades privadas como os serviços sociais autônomos não encontra óbice constitucional, desde que a atividade privada não seja exercida sobre a parcela da atividade estatal que, por força da normatividade constitucional, deve ser exercida única e exclusivamente pelo Estado.

\section{REFERÊNCIAS}

ABBOUD, Georges; CARNIO, Henrique Garbellini; OLIVEIRA, Rafael Tomaz de. Introdução ao direito: teoria, filosofia e sociologia do Direito. 4. ed. São Paulo: Ed. RT, 2019.

BARROSO, Luís Roberto. Curso de direito constitucional contemporâneo: os conceitos fundamentais e a construção do novo modelo. 8. ed. São Paulo: Saraiva Educação, 2019.

BORGES, Alice Gonzalez. Serviços Sociais Autônomos: natureza jurídica. Revista Eletrônica de Direito do Estado (REDE), Salvador, Instituto Brasileiro de Direito Público, 26, abr.-maio-jun. 2011. Disponível em: [www.direitodoestado.com/ revista/REDE-26-ABRIL-2011-ALICE-GONZALEZ-BORGES.pdf]. Acesso em: 20.11.2019.

CAVALCANTI, Themistocles Brandão. Autarquias: natureza jurídica do Serviço Social do Comércio. Revista de Direito Administrativo. Rio de Janeiro: FGV,v. 19, jan. 1950.

CUÉLLAR, Leila. Os novos serviços sociais autônomos: exame de um caso. Revista Eletrônica sobre a Reforma do Estado (RERE), Salvador, Instituto Brasileiro de Direito Público, n. 14, jun.-jul.-ago. 2008. Disponfivel em: [www.direitodoestado.com.br/rere.asp]. Acesso em: 10.11.2019.

GROSS, Aeyal M. Human rights and American public law scholarship: a comment on Robert Post. Theoretical inquiries in Law 2.1. (2001). Disponivel em: [www7.tau.ac.il/ojs/index.php/til/article/view/207/183]. Acesso em: 28.12.2019.

FURTADO, Lucas Rocha. Curso de direito administrativo. 5. ed. Belo Horizonte: Fórum, 2016.

HÄBERLE, Peter. Direitos fundamentais no Estado prestacional. Porto Alegre: Livraria do Advogado, 2019.

JELLINEK, Georg. Teoria general del Estado. Trad. Espan. México: FCE, 2000.

NUNESJUNIOR, Vidal Serrano. A cidadania social na Constituição de 1988: estratégias de positivação e exigibilidade judicial dos direitos sociais. São Paulo: Verbatim, 2009.

MEIRELLES, Hely Lopes. Direito administrativo brasileiro. 35. ed. São Paulo: Malheiros, 2009. 
MENDES, Gilmar Ferreira. Os direitos fundamentais eseus múltiplossignificados na ordem constitucional. Revista Diálogo Jurídico, Salvador: CAJ - Centro de AtualizaçãoJurídica, n. 10, jan. 2002. Disponível em: [https://ivros-e-revistas. vlex.com.br/vid/fundamentais-multiplos-significados-59306903?_ga= 2.155787583.520207255.1578327971-1389459247.1578327971]. Acesso em: 06.01.2020.

MONACILIUNI, Mara. Diritto pubblico. 3. ed. Napoli: Edizes, 2013.

SHAMIR, Hila. The Public/Private Distinction Now: The Challenges of Privatization and of the Regulatory State. Theoretical Inquiries in Law, v. 15, n. 1, January 2014, p. 1-25. Disponível em: [www7.tau.ac.il/ojs/index.php/til/article/view/527/491]. Acesso em: 28.12.2019.

XINGZHONG YU. State Legalism and the Public/Private Divide in Chinese Legal Development. Theoretical Inquiries in Law, v. 15, n. 1, January 2014, p. 27-51. Disponivel em: [www7.tau.ac.i1/ojs/index.php/til/article/view/527/491]. Acesso em: 28.12.2019.

\section{Pesquisas do EDITORIal}

\section{Veja também Doutrinas relacionadas ao tema}

- A administração pública brasileira. Uma contribuição ao estudo do estado-empregador, de Floriano Corrêa Vaz da Silva - RDT 20/97-121 (DTR|1979|141);

- A contratação por inexigibilidade de escritório de advocacia no Sistema "S": o caso do Sebrae, de Edvaldo Nilo de Almeida - RDAl 12/141-157 (DTR|2020|1780); e

- Serviços sociais autônomos: organização interna, proibição do retrocesso social e cláusulas pétreas, de Edvaldo Nilo de Almeida - RDAl 15/147-167 (DTR|2020|14262). 